OPEN ACCESS

Edited by:

Norbert Stefan,

University of Tübingen, Germany

Reviewed by:

Vibeke H. Telle-Hansen,

Oslo Metropolitan University, Norway

Marijana Todorcevic,

Oxford Centre for Diabetes,

Endocrinology and Metabolism

(OCDEM), United Kingdom

*Correspondence:

Kylie Kavanagh

kkavanag@wakehealth.edu orcid.org/0000-0001-8772-6186

Specialty section:

This article was submitted to

Nutrition and Metabolism,

a section of the journal

Frontiers in Nutrition

Received: 02 November 2020

Accepted: 05 January 2021

Published: 17 February 2021

Citation:

Ruggiero AD, Key C-CC and Kavanagh K (2021) Adipose Tissue Macrophage Polarization in Healthy and Unhealthy Obesity.

Front. Nutr. 8:625331.

doi: 10.3389/fnut.2021.625331

\section{Adipose Tissue Macrophage Polarization in Healthy and Unhealthy Obesity}

\author{
Alistaire D. Ruggiero ${ }^{1}$, Chia-Chi Chuang $K^{2} y^{2}$ and Kylie Kavanagh ${ }^{1,3 *}$ \\ ${ }^{1}$ Section on Comparative Medicine, Department of Pathology, Wake Forest University School of Medicine, Winston-Salem, \\ NC, United States, ${ }^{2}$ Section on Molecular Medicine, Department of Internal Medicine, Wake Forest University School of \\ Medicine, Winston-Salem, NC, United States, ${ }^{3}$ Department of Biomedicine, University of Tasmania, Hobart, TAS, Australia
}

Over 650 million adults are obese (body mass index $\geq 30 \mathrm{~kg} / \mathrm{m}^{2}$ ) worldwide. Obesity is commonly associated with several comorbidities, including cardiovascular disease and type II diabetes. However, compiled estimates suggest that from 5 to $40 \%$ of obese individuals do not experience metabolic or cardiovascular complications. The existence of the metabolically unhealthy obese (MUO) and the metabolically healthy obese $(\mathrm{MHO})$ phenotypes suggests that underlying differences exist in both tissues and overall systemic function. Macrophage accumulation in white adipose tissue (AT) in obesity is typically associated with insulin resistance. However, as plastic cells, macrophages respond to stimuli in their microenvironments, altering their polarization between pro- and anti-inflammatory phenotypes, depending on the state of their surroundings. The dichotomous nature of $\mathrm{MHO}$ and $\mathrm{MUO}$ clinical phenotypes suggests that differences in white AT function dictate local inflammatory responses by driving changes in macrophage subtypes. As obesity requires extensive AT expansion, we posit that remodeling capacity with adipose expansion potentiates favorable macrophage profiles in $\mathrm{MHO}$ as compared with MUO individuals. In this review, we discuss how differences in adipogenesis, AT extracellular matrix deposition and breakdown, and AT angiogenesis perpetuate altered AT macrophage profiles in MUO compared with $\mathrm{MHO}$. We discuss how non-autonomous effects of remote organ systems, including the liver, gastrointestinal tract, and cardiovascular system, interact with white adipose favorably in $\mathrm{MHO}$. Preferential AT macrophage profiles in $\mathrm{MHO}$ stem from sustained AT function and improved overall fitness and systemic health.

Keywords: adipose, macrophage, metabolically healthy, metabolically unhealthy, obesity

\section{INTRODUCTION}

As of February 2020, more than 1.9 billion adults worldwide were overweight [body mass index (BMI): $25-29.9 \mathrm{~kg} / \mathrm{m}^{2}$ ], and over 650 million were obese (BMI $\left.\geq 30 \mathrm{~kg} / \mathrm{m}^{2}\right)(1)$. Obesity decreases lifespan and increases the risk of developing hypertension, dyslipidemia, and type II diabetes (T2D) (2-4). Despite the number and variety of deployed weight-loss interventions, very few overweight or obese patients maintain weight loss over time, and globally, the number of obese individuals continues to increase (5). Across the BMI spectrum, not all obese individuals suffer the same comorbidities. Roughly $60 \%$ of obese individuals present with dysglycemia, hypertension, 
and/or dyslipidemia, and cutoff criteria associated with each of these maladies define obesity as either healthy [metabolically healthy obese $(\mathrm{MHO})$ ] or unhealthy [metabolically unhealthy obese (MUO)] $(6,7)$. The majority of individuals are classified as MUO; however, between 5 and $40 \%$ of obese individuals do not present with metabolic abnormalities and are defined as $\mathrm{MHO}$ (6-8). Definitions of MHO vary, as some studies identify only insulin-sensitive individuals as MHO, whereas others identify individuals with two or fewer metabolic abnormalities as MHO $(7,9,10)$. A recently proposed definition of MHO identifies individuals based on the diagnosis of obesity and the following criteria: serum triglycerides $\leq 150 \mathrm{mg} / \mathrm{dl}$, HDL-cholesterol concentrations $>40 \mathrm{mg} / \mathrm{dl}$ in men or $>50 \mathrm{mg} / \mathrm{dl}$ in women, systolic blood pressure $\leq 130 \mathrm{mmHg}$, diastolic blood pressure $\leq 85 \mathrm{mmHg}$, no antihypertensive treatment as an alternative indicator, fasting blood glucose $\leq 100 \mathrm{mg} / \mathrm{dl}$, and no treatment with glucose lowering agents (11). Significant controversy exists over the definitions and stability of MHO classifications. There is no universally accepted definition of $\mathrm{MHO}$; many $\mathrm{MHO}$ individuals progress to MUO over time, and, although $\mathrm{MHO}$ individuals do have higher all-cause mortality and an increased risk of cardiovascular events compared with healthy lean individuals $(12,13)$, they are at a decreased risk of cardiovascular complications and all-cause mortality compared with the MUO individual. Despite this controversy, understanding the biological mechanisms that maintain metabolic health with overt obesity would aid the development of therapeutics to convert MUO individuals to $\mathrm{MHO}$ and ultimately reduce the financial burden of obesity-related comorbidities.

Although obesity results in white adipose tissue (AT) expansion, maintenance of metabolic function may underlie MHO individuals' superior metabolic homeostasis. AT functions as an endocrine organ that maintains energy equilibrium, but function can differ by location. White AT accumulates throughout the body, including in the epicardial, mesenteric, omental, retroperitoneal, gonadal, subcutaneous abdominal, gluteal, and femoral regions (14). Intra-abdominal, or visceral, and subcutaneous white AT depots perform different functions and thus differentially impact metabolic health. Visceral AT accumulation is positively associated with cardiometabolic risk factors (15) and correlation with decreased insulin sensitivity (16). On the contrary, subcutaneous white AT accumulation protects against cardiometabolic risk factors (15) and corresponds with maintained insulin sensitivity (17), as evidenced by subcutaneous adipose transplantation into visceral depots alleviating metabolic dysregulation (18). Both adipocytes and immune cells in AT express and secrete bioactive hormones and signaling proteins that regulate metabolism (19-21). The goal of this review is to summarize macrophages as key AT immune cells and their influences, which drive tissue function (Figure 1). Elucidating changes in white AT composition is crucial to unraveling the mechanisms behind the observed metabolic differences between $\mathrm{MHO}$ and $\mathrm{MUO}$ groups.

Obesity-associated AT expansion often results in the accumulation of immune cells, including macrophages, contributing to low-grade chronic inflammation. Macrophages are the most abundant leukocytes in AT and assist in regulating physiological processes, including tissue remodeling and insulin sensitivity. Macrophage accumulation was originally thought to be universally pro-inflammatory and contributory to insulin resistance. However, macrophage subtypes stimulate different responses within AT. Macrophage subtypes exist along a continuum, as they demonstrate variable metabolic activation and ranges in inflammatory signaling $(22,23)$. As such, they are often classified by whether they are more pro-inflammatory or more anti-inflammatory. M1 macrophages are thought to be more pro-inflammatory and secrete pro-inflammatory cytokines that ultimately inhibit proper insulin signaling in adipocytes $(23,24)$. Contrarily, M2 macrophages are thought to be more anti-inflammatory and secrete anti-inflammatory cytokines that maintain functional insulin signaling $(23,24)$.

In obese states, macrophages play crucial roles in damage response. Macrophage polarization patterns are influenced by environmental cues and inflammatory signaling (23), and macrophages accumulate when danger signals propagate and incite more inflammation to manage their resolution. In obese states, macrophages clear dead adipocytes and other cell debris, exocytose excess lipid, secrete both pro- and antiinflammatory cytokines, and contribute to adipose remodeling (23). Macrophage responses are interrupted by insulin resistance, hypoxia, and reactive oxygen species generation, metabolic endotoxemia or cell senescence, and death. While macrophage accumulation in obese individuals is typically affiliated with inflammation and these downstream consequences, healthy obese individuals do not demonstrate the same levels of inflammation as their MUO counterparts. In this review, we discuss how differences in white AT components give rise to contrasting macrophage $\mathrm{M}$-phenotypes in $\mathrm{MHO}$ compared with MUO persons. We also discuss how diet and aspects of systemic metabolic health impact AT macrophages.

\section{ADIPOSE MACROPHAGE SUBTYPES}

Obesity alone incites the recruitment and proliferation of AT macrophages, the predominant adipose leukocyte population $(25,26)$. As plastic cells that respond to their microenvironments, macrophages range from highly pro-inflammatory, or M1-like, to highly anti-inflammatory, or M2-like (27). M1 macrophages fight against intracellular pathogens, are induced by pro-inflammatory factors including lipopolysaccharide and interferon- $\gamma$, and secrete inflammatory cytokines including interleukin (IL)-6, IL$1 \beta$, and monocyte chemoattractant protein-1 (MCP-1) (28). Hematopoietic-derived M1 macrophages utilize glycolysis and are recruited into AT and where they can proliferate (29-31). M2 macrophages, on the other hand, contribute to tissue repair and produce anti-inflammatory cytokines, including IL-4 and IL-13. Contrary to M1 macrophages, yolk sac-derived M2 macrophages utilize oxidative phosphorylation (31). White AT homeostasis requires a balance of both these pro- and anti-inflammatory macrophage subtypes. Excess M1 macrophage infiltration results in increased tissue inflammation, whereas an overabundance of M2 macrophages can lead to aberrant fibrogenesis, limiting the remodeling required for AT to respond to changing lipid 


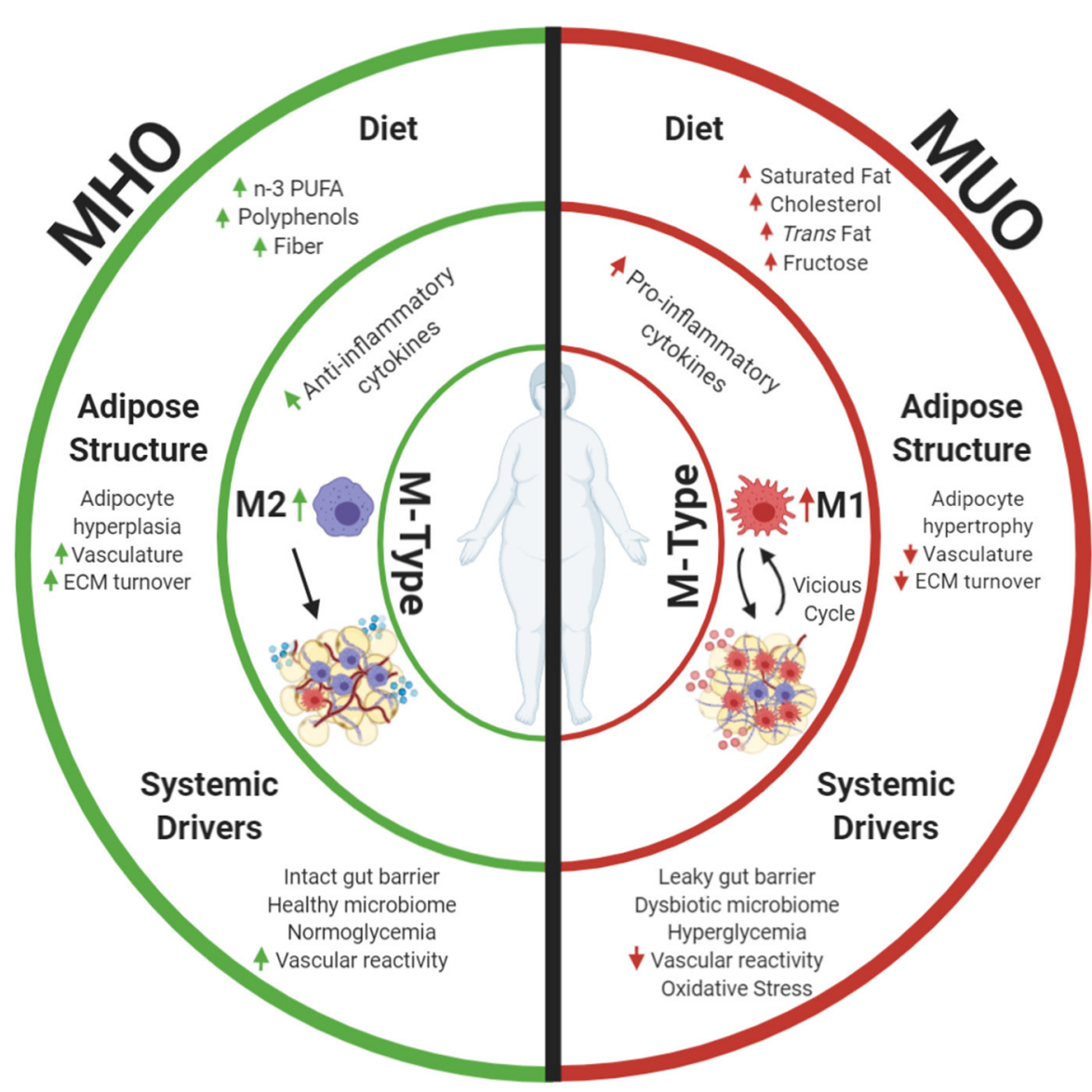

FIGURE 1 | Metabolically healthy obesity (MHO) and metabolically unhealthy obesity (MUO) may be defined by differences in AT. This review focuses on macrophage phenotypes (M-Types) as a key element driving adipose health, as these immune cells have potent effects on the local AT niche and are influenced by diet and other systemic health characteristics. Differences in dietary components and aspects of adipose expansion perpetuate MHO and MUO adipose macrophage phenotypes. Increased consumption of omega 3 polyunsaturated fatty acids (n-3 PUFAs), polyphenols, and fiber results in anti-inflammatory adipose macrophage (M2) programming in $\mathrm{MHO}$. These dietary components combined with improved white adipose adipogenesis and corresponding adipocyte hyperplasia increase tissue vascularization and extracellular matrix (ECM) turnover, and downstream anti-inflammatory signaling propagates anti-inflammatory M2 macrophage proliferation while abating harmful pro-inflammatory M1 macrophage recruitment into tissue. Parallel to effects of diet and adipose structure, systemic drivers, including functional liver-adipose cross talk and improved vasoreactivity, also decrease MHO AT pro-inflammatory signaling and maintain insulin sensitivity. Alternatively, increased consumption of saturated fat, cholesterols, trans fat, and fructose incites pro-inflammatory macrophage recruitment in MUO adipose. Consumption of these dietary components in conjunction with dysfunctional adipogenesis results in adipocyte hypertrophy. This combined with decreased angiogenic signals, disrupted ECM turnover, and downstream pro-inflammatory cytokine secretion stimulates pro-inflammatory M1 macrophage recruitment. Systemic dysfunction in the form of a decreased vasoreactivity and oxidative stress concurrently fosters insulin resistance while promoting pro-inflammatory M1 macrophage recruitment into MUO adipose. Once M1 macrophages enter the tissue, they secrete additional pro-inflammatory cytokines that recruit more M1 macrophages. This vicious cycle of inflammation, perpetuation of unhealthy AT, and greater multisystemic dysfunction characterize MUO individuals who are defined by increased expression of metabolic syndrome components. Created with Biorender.com.

storage needs $(32,33)$. In diet-induced obese states, macrophage polarization shifts from a 4:1 M2-to-M1 ratio in lean animals to a 1.2:1 ratio in obese animals, as M1 macrophages are recruited into white AT (29).

MHO individuals display an anti-inflammatory adipose macrophage profile that more closely resembles that of metabolically healthy lean individuals, including an increased M2:M1 ratio (34). Of note, $\mathrm{MHO}$ individuals likely accumulate metabolically active adipose macrophages, which is a subtype that may be distinct from coarsely defined M1 or M2. Although we will focus primarily on M1 and M2 macrophages in the remainder of this text, metabolically active macrophages are associated with decreased nicotinamide adenine dinucleotide phosphate oxidase 2 , which reduces the inflammation associated with obesity and downstream insulin resistance $(30,35,36)$. These macrophages are thought to better regulate lipid, catecholamine, and iron availability and perform other functions, including modulating local inflammation and clearing dead adipocytes during prolonged obesity $(30,35,36)$. This suggests that, in contrast to MUO, MHO individuals' antiinflammatory AT macrophage profile helps maintain insulin and glucose regulation and deters pro-inflammatory macrophage 
recruitment. In the following sections, we will discuss the relationships between aspects of AT function, macrophage polarization, and metabolic regulation in $\mathrm{MHO}$ compared with MUO.

\section{ADIPOCYTE FUNCTION AND ADIPOGENESIS}

MHO adipocyte function mediates anti-inflammatory AT macrophage activation and polarization (37). Adipocytes secrete cytokines, depending on their inflammatory state, that influence immune cells. Secretion of Th2 cytokines, including IL4 and IL-13, induces macrophage peroxisome proliferatoractivated receptor (PPAR) $\delta$ activation, a regulator of fatty acid metabolism (38), which also improves whole-body insulin sensitivity (39). Insulin-sensitive obese individuals have higher PPAR $\gamma$ (i.e., PPAR $\gamma 2$ ) messenger RNA (mRNA) expression levels in peripheral blood mononuclear cell and their visceral adipose than do insulin-resistant obese individuals (40,41). Ablation of both PPAR $\gamma$, a regulator of adipogenesis and lipogenesis, and PPAR $\delta$ renders macrophages unable to transition to the M2 subtype $(38,42,43)$. Therefore, in MHO individuals, adipocyte cytokine secretion and its downstream effects on fatty acid metabolism and adipogenesis regulators incite M2 macrophage polarization and whole-body insulin sensitivity while promoting sufficient adipogenesis (i.e., proliferation and differentiation of preadipocytes) to manage the concurring nutrient overload.

Fluctuations in AT macrophage ratios correspond to changes in preadipocyte differentiation and adipogenic signaling. The factors secreted by pro-inflammatory M1 macrophages possess anti-adipogenic properties (44). Unlike M1 macrophages, both M2 macrophages and inactive macrophages promote preadipocyte survival by releasing a platelet-derived growth factor (PDGF) (45). However, excess M2 macrophages have been shown to impair preadipocyte differentiation through the transforming growth factor-beta (TGF- $\beta$ ) pathway (46). The effects of AT macrophage balance on preadipocyte differentiation and adipose expansion require further investigation (47); however, differences in the AT macrophage profiles of MHO and MUO individuals likely drive the rate and format of adipogenesis, as in vitro differentiation protocols illustrate that adipogenesis is greater in MHO than MUO people (48-51). The nuclear hormone receptor PPAR $\gamma$ acts as a master transcription factor of adipocyte differentiation by inducing and maintaining the expression of key adipogenic genes, such as GLUT4 and adiponectin, which are necessary for normal adipocyte function and downstream insulin sensitivity (52). Diabetic patients treated with PPAR $\gamma$-activating thiazolidinediones, a class of antidiabetic drugs, often experience weight gain in the form of subcutaneous AT expansion. Accordingly, the subcutaneous AT expansion that occurs through adipocyte hyperplasia (increasing number of cells through differentiation of new adipocytes) appears metabolically favorable and contributes to systemic insulin sensitization (53), and the same PPAR $\gamma$ signaling promotes an M2-positive AT balance. In obese states, AT macrophages provide signals that communicate with mature adipocytes and preadipocytes to incite either adipocyte hypertrophy or preadipocyte differentiation and adipocyte hyperplasia. In $\mathrm{MHO}$, de novo adipogenesis driven by improved glucose uptake and anti-inflammatory signaling-including increased PPAR $\gamma$ and adiponectin-results in smaller, more numerous adipocytes (54); the resulting adipocyte hyperplasia maintains a more anti-inflammatory AT macrophage profile (54). In MUO, hypertrophic adipocytes communicate with recruited M1 macrophages and secrete proinflammatory leukotrienes, such as LTB4, which inhibit insulin signaling in metabolic tissues and thus further recruit more proinflammatory macrophages (55). Proteomic analyses of visceral AT from T2D MUO obese individuals reveal mitochondrial dysfunction and reduced adipocyte differentiation, which additionally incites M1 macrophage recruitment (56). This vicious cycle continues with tumor necrosis factor-alpha and IL$1 \beta$ secreted by M1 macrophages, further impairing adipogenic differentiation, with reduced adipogenic gene expression in subcutaneous AT and, in some cases, increased numbers of small adipocytes $(48,57,58)$. In contrast, normoglycemic obese individuals show an increase in the percent of adipose progenitors within their tissue compared with both pre-diabetic and T2D obese subjects (59). MHO individuals benefit from a positive insulin sensitizing cycle, where anti-inflammatory signals from adipocytes result in M2 macrophage polarization, which promotes healthy adipocyte hyperplasia and further antiinflammatory signaling from adipocytes.

\section{EXTRACELLULAR MATRIX REMODELING}

Healthy AT expansion requires extracellular matrix (ECM) remodeling. Adipocytes are surrounded by a network of ECM proteins that serve as a mechanical support and respond to different signaling events (60). AT expansion relies on adaptive cellular and extracellular responses to prevent ectopic lipid deposition and lipotoxicity (61-63). Within AT, collagens produced primarily by adipocytes and endothelial cells comprise most non-cell tissue mass, whereas integrins are the major tissue receptors for cell adhesion to ECM proteins $(64,65)$. Increased interstitial fibrosis due to excess collagen deposition likely decreases ECM flexibility and reduces tissue plasticity, which leads to adipocyte dysfunction and immune cell infiltration (66). Insulin-resistant individuals demonstrate aberrant ECM deposition and insufficient ECM breakdown $(59,67)$.

Important protein families that comprise the ECM include matrix metalloproteinases (MMPs), enzymes that process and degrade pericellular substrates and play a vital role in regulating ECM remodeling in normal and disease states (68). Tissue inhibitors of metalloproteinases (TIMPs), which comprise a family of four protease inhibitors, inhibit MMPs to achieve a balance in production and breakdown (69). Adipose expression of MMP-9, increased in MUO compared with MHO $(38,70)$, positively correlates with insulin resistance and cardiovascular risk in obese persons. Similarly, visceral AT MMP-14 expression correlates with adipose accumulation and insulin resistance in women (71). MMP-11 is also increased in the white adipose of obese insulin-resistant mice (72). TIMP-3 regulates white 
adipose inflammation and insulin sensitivity, and its deletion in mice increases M1 macrophage accumulation in white AT (73), whereas its overexpression in macrophages resulted in improved glucose tolerance and insulin sensitivity and decreased inflammation in high-fat diet-fed mice (74).

Individuals with worsening glycemic control exhibit excess AT deposition of collagens I, III, IV, and VI (59). Collagen VI gene expression coincides with more visceral adipose mass and pro-inflammatory macrophage accumulation (75, 76). Excess collagen VI deposition imparts stress by inhibiting adipocyte expansion (60). AT fibrosis creates rigidity, restrains adipocyte expansion, and, ultimately, triggers adipocyte inflammation in response to the increased mechanical stress. Collagen IV, which accounts for up to $50 \%$ of the basement membrane, also increases with TGF $\beta-1$ and TGF $\beta$-3 gene expression in human subcutaneous adipose, resulting in pro-inflammatory and pro-fibrotic phenotypes (77). Increases in collagens, including Col24 $\alpha 1$, are associated with insulin resistance in AT and skeletal muscle $(78,79)$. Also, gene expression of CD44, which regulates cell-cell and cell-matrix interactions, is 3-fold higher in subcutaneous AT of MUO individuals, and CD44 density on macrophages is associated with the M1 phenotype (80). These data indicate that a vicious cycle of aberrant ECM turnover and increased inflammatory signaling, including M1 macrophage recruitment, results in insulin resistance in obese AT.

$\mathrm{MHO}$ individuals possess improved ECM turnover rates, as their more flexible ECM constitution allows for increased lipid storage. As previously mentioned, the expandability of $\mathrm{MHO}$ individuals' subcutaneous AT is thought to contribute to their decreased visceral AT accumulation and healthier metabolic profile (60), resulting in less cell death and decreased M1 macrophage recruitment (23). Decreased amounts of MMPs and TIMPs, including TIMP-1, allow MHO adipocytes to differentiate more readily (81), as insulin-sensitive obese patients demonstrate less fibrosis than diabetic obese patients before and after bariatric surgery (82). Improving ECM turnover in MUO individuals could permit increased subcutaneous fat mass and ameliorate metabolic dysfunction and shifts in macrophage balance (83). M2 secretion of TGF- $\beta$ provides essential structural support and necessary remodeling. However, in pathological instances, this secretion results in aberrant fibrosis development. Secretion of TGF- $\beta$ by M2 macrophages is intended to promote antiinflammatory tissue remodeling, though if aberrant, results in increased collagen deposition, downstream fibrosis, and insulin resistance (84). MHO individuals' M2/M1 AT macrophage ratio, corresponding TGF- $\beta$ secretion, and adequate ECM turnover allow for decreased adipocyte mechanical stress.

Genes and gene product regulation in different obesity subtypes also determine ECM turnover by controlling macrophage polarization. For example, microRNAs (miRNAs) alter gene expression and modulate downstream glucose metabolism and insulin sensitivity in obesity (85), and exosomes from AT-derived stem cells control M2 macrophage polarization (86). Specifically, exosomal miRNA-34a secreted by adipocytes suppresses M2 macrophage polarization and promotes obesityinduced adipose inflammation and metabolic dysfunction (87), whereas increased expression of miRNA-145 in visceral adipose reduces macrophage expression of pro-inflammatory cytokines through adenosine diphosphate ribosylation factor 6 (88). MiRNA-145 also promotes preadipocyte differentiation and angiogenesis, leading to healthier AT (89). Adipocyte-derived exosomes contain many miRNAs still being characterized, such as miRNA-23b, miRNA-148b, and miRNA-4429, which are expected to alter TGF- $\beta$ signaling and potentially mitigate downstream fibrosis (90). For example, upregulation of miRNA23b mitigated kidney fibrosis in leptin-deficient mice (91), suggesting that exosomal miRNAs secreted from MHO adipose likely promote both anti-inflammatory macrophage polarization and preadipocyte differentiation while mitigating fibrosis.

Current data indicate that $\mathrm{MHO}$ adipose corresponds with sufficient ECM deposition and breakdown coupled with balanced AT macrophage populations and anti-fibrotic/proadipogenic miRNA secretion. Of note, miRNA promotion of preadipocyte differentiation co-occurring with new blood vessel formation (89) highlights that adipose expansion necessitates vascularization.

\section{ANGIOGENESIS}

Adipose vascularity dictates tissue metabolism and insulin sensitivity. In obese states, AT expansion requires neovascularization that allows for sufficient oxygenation, nutrient delivery, and adipocyte differentiation. Adipose microvasculature plays a primary role in glucose homeostasis, as impaired tissue perfusion results in decreased glucose uptake and is a hallmark of T2D (92). Adipocyte hypertrophy that can occur within just three days of high-fat diet consumption incites signals to increase angiogenesis and alleviate hypoxia (93). Successful neovascularization and its concomitant ECM remodeling reduce hypoxia to maintain AT health (94).

MHO individuals typically accumulate subcutaneous white AT, which possesses improved angiogenic capabilities as compared with visceral adipose (95). MHO individuals maintain peripheral capillary density similar to metabolically healthy lean individuals, which allows for enhanced nutrient flow, and demonstrate improved fitness compared with MUO (96-98). Vascular endothelial growth factor (VEGF) contributes to new blood vessel formation, as it induces the growth of both preexisting and new vessels (65). Adequate AT VEGF signaling in high-fat diet-fed mice protected the animals against insulin resistance by reducing hypoxia and, in turn, increasing their M2/M1 tissue macrophage profile (99-101). Increases in capillary density coincided with improvements in metabolic function in obese rats with metabolic syndrome (98). Improved fitness achieved through aerobic training of high-fat diet-fed rats increased AT capillary density and increased the number of M2 tissue macrophages (102).

Improved vascularity in $\mathrm{MHO}$ AT also is likely to increase numbers of adipose progenitor cells, as such cells reside within adipose vasculature (103). Increased numbers of adipose progenitors allow for hyperplastic expansion, which perpetuates an anti-inflammatory immune profile, including an increased M2/M1 macrophage ratio, as demonstrated by increased 
adipocyte hyperplasia in the subcutaneous AT of obese women (104). These data suggest that hyperplastic subcutaneous depot expansion that co-occurs with increased AT vascularity facilitates an anti-inflammatory AT milieu in the MHO.

Prolonged hyperglycemia makes the cells within AT vessels susceptible to injury and promotes microvascular dysfunction. A vicious cycle occurs in MUO patients, where impaired glycemic control worsens vascular reactivity, which then exacerbates AT hypoxia, inflammation, and tissue insulin resistance. MUO patients have a $44 \%$ decrease in capillary density and 58\% lower VEGF signaling in the subcutaneous adipose, highlighting the occurrence of vascular rarefaction with hyperglycemia (105). Likewise, VEGF expression in both subcutaneous and visceral adipose decreases in a stepwise fashion with worsening insulin resistance (106). ECM dysregulation contributes to insufficient vascularization, as obese patients with T2D demonstrate increased basement membrane thickness (59) and higher collagen VI synthesis, which correlated inversely with AT oxygenation in MUO patients (105). The two-hit process of impaired ECM remodeling and poor vascularization stimulates a pro-inflammatory immune cell response in MUO adipose, exemplified by CD68 mRNA and macrophage inflammatory protein $1 \alpha$ expression inversely correlating with AT oxygenation in MUO subjects (105). Accordingly, contrary to MHO adipose, decreased angiogenic capacity and increased vessel injury in MUO adipose result in increased pro-inflammatory M1 macrophage recruitment and pro-inflammatory signaling.

As angiogenic capacity influences adipose macrophage subtypes, existing macrophages in adipose impact angiogenesis. Macrophage deletion results in a reduction of vascular density in AT (107). Macrophages are a significant source of AT PDGF, which assists with blood vessel growth and repair of damaged vessels; their deletion also leads to a significant reduction in PDGF mRNA (108). M2 macrophages promote angiogenic signaling, as evidenced by increased endothelial cells and tubular structures in subcutaneous adipose post-M2 macrophage injection (109). M2 macrophage polarization, but not the M1 phenotype, caused a substantial downregulation of TIMP-1 expression, resulting in the production of the angiogenic activated zymogen, proMMP-9 (110). These data suggest that the anti-inflammatory $\mathrm{MHO}$ adipose macrophage profile stimulates angiogenesis, which not only ensures sufficient AT nutrient supply but also contributes to MHO individuals' improved fitness and systemic health.

\section{NUTRITION AND ADIPOSE MACROPHAGE PROGRAMMING}

Nutrient overload caused by excess food consumption is the most common initial trigger for obesity, and diet represents the paramount environmental health factor that is both modifiable and variable across populations. High caloric intake per se can effect macrophage polarization (27); however, dietary factors can influence either augmentation of M1 subtype abundance or support M2 programming. Macrophages have evolved to be effective responders to pathogen-associated molecular patterns (PAMPs) and damage-associated molecular patterns (DAMPs), which share common effector pathways. These patterns have been best explored with "microbial" inputs where these pathogen signals (endotoxin, lipoproteins, membrane proteins, peptidoglycans, DNA fragments, and lipoteichoic acid are examples) bind to receptors and initiate both phagocytosis/destruction and activation of inflammatory outcomes crucial to effective innate immunity (111). Toll-like receptors (TLRs), scavenger receptors, and mannose receptors are pattern recognition receptors present in all macrophages, and binding and activation of the inflammasome and subsequent release of cytokines and interferons lead to polarization toward the M1 type of local resident macrophages, recruitment of circulating monocytes for activation, and proliferation of macrophages in situ (112).

Diet has profound effects on the magnitude of DAMPs and PAMPs to which adipose macrophages are exposed. One of the important observations made in people was coined "metabolic endotoxemia," whereby caloric excess was related to increased biomarkers of microbial translocation, such as lipopolysaccharide-binding protein 1 (LBP1) (113). LBP1 is released from the liver into the circulation in response to PAMPs and functions as a co-receptor for TLRs present on the macrophage cell membrane, thus initiating inflammatory responses in peripheral tissues, such as adipose $(114,115)$. In addition to just caloric excess, specific dietary components are known to induce LBP1 and PAMP signaling through modulation of the microbial interactions at the intestinal mucosal barrier. Fructose is the best described dietary factor proven to increase intestinal barrier dysfunction in rodents, humans, and non-human primates (116-120). Fructose is additionally associated with excess caloric consumption, obesity, and metabolic diseases, such as diabetes and metabolic-associated fatty liver, and these disease states further augment macrophage accumulation and the inflammatory cycle of insulin resistance in AT (27). Lipoproteins are additionally recognized as PAMPs, and low-density lipoproteins reliably increase in concentration in response to caloric excess and fructose exposure, as the liver packages and processes TGs for export (121). This lipoproteindelivered $\mathrm{TG}$ is the substrate for AT to uptake and store peripherally, which, in unhealthy obesity, may not be an efficient process. Impaired insulin sensitivity and excess adipocyte hypertrophy lead to hypoxia, further inflammatory signaling and macrophage recruitment, and even adipocyte apoptosis or necrosis - the sequelae being more local DAMPs to drive local macrophages to respond, recruit, and additionally augment the M1 response.

The endotoxemia resulting from caloric excess or dietary fructose has been described as sterile; however, more recently, antibiotic and probiotic therapy deployed to modify the pathogen response has shown effectiveness in improving inflammatory and metabolic outcomes (117). More evidence to suggest that local adipose PAMP responses are to actual pathogens includes the recent demonstration of an adipose microbiome in obese people (122-124). These bacteria are confirmed to include whole live organisms and be present in the circulation and visceral and subcutaneous AT depots (124). From the data suggesting that dietary calories and ingredients increase microbial translocation and shape the microbiome, it is likely that the number and 
type of microbes filtered out into adipose also are diet driven (125) and will influence the abundance and polarization of adipose macrophages.

Saturated fat is another dietary component with the ability to function as a PAMP/DAMP. Structurally, a longer chain of single carbon-carbon bonds may mimic the saturated fatty acids in phospholipids of most microbial membranes and the long fatty acid chains incorporated in the structure of endotoxins, which in intact gram-negative microbes reside in the outer membrane (126). Saturated fat intake has been related to endotoxemia, but studies that include calorie control are not available, and caloric excess alone is sufficient to elevate LBP1 and induce peripheral inflammation (127-129). Similarly, trans-fatty acids structurally resemble saturated fatty acids and are presumed to act as pro-inflammatory danger signals and a potent dietary ingredients famous for induction of metabolically unhealthy obesity $(130,131)$. A diet rich in unhealthy attributes, such as excess caloric amounts, high fructose or added sugars, cholesterol (132), saturated and/or trans-fatty acids, all drive macrophage activation through highly conserved pathways evolved to detect pathogens and resolve tissue damage (133). The result perpetuates an inflammatory state and M1 phenotypic predominance in AT in response to signals that indicate the need for active phagocytic and antigen presentation functions. Depot differences are not well-described; however, some evidence for dietary factors inducing intra-abdominal fat shifts do exist. Examples include trans-fat consumption being linked to visceral fat accumulation, and in an obese patient cohort, the abundance of ectopic bacteria in omental fat tissue was slightly higher than that in subcutaneous fat, both of which are consistent with the body of knowledge that indicates intra-abdominal AT is more contributory to unhealthy obesity than is subcutaneous fat expansion $(122,124)$.

Few dietary factors directly influence macrophages positively to effect an M2 inflammation-resolving state. Polyunsaturated fatty acids (PUFAs) do have a direct role on macrophage function (134), whereas most dietary components have indirect contributions to adipose health and consequential reductions in DAMP/PAMP sensing by local macrophage populations (135). These indirect effects will not be discussed, but examples include dietary fiber, which shifts the microbiome and improves mucosal barrier function, thus decreasing LBP1 and endotoxemia (136-138), dietary components, such as isoflavones, which are rich in fermented foods, and polyphenols, which are rich in fruits and vegetables. Isoflavones can have a lipid-lowering effect (139), thus decreasing lipoprotein sensing by scavenger receptors, and can have estrogen receptor (ER) activity, which indirectly can reduce inflammation and promote vascular reactivity. Macrophages express ER (predominantly $\alpha$-isoforms and G-protein coupled ER1), and dietary isoflavones can bind and decrease Nuclear factor-kappa B (NF-кB) activation and cholesterol oxidation in the context of lipid and cholesterol exposure (140), thus facilitating or maintaining M2 polarization in culture and vascular tissue, an effect likely to be also seen in adipose macrophages (141). Polyphenols can be effective free radical scavengers, thus reducing local inflammation and tissue damage signaling $(142,143)$.
Omega-3 polyunsaturated fatty acids ( $n-3$ PUFA) cannot be synthesized de novo by humans due to the lack of delta12 and delta-15 desaturase enzymes and must, therefore, be acquired from the diet (144). The major n-3 fatty acid in the diet, $\alpha$-linolenic acid (18:3n-3), can be converted to other more anti-inflammatory lipids, such as eicosapentaenoic acid (20:5n-3), docosahexaenoic acid (22:6n-3), and the less recognized docosapentaenoic acid (22:5n-3), which can be directly sourced through consumption of fish and derived fish oils. The utilization of dietary n-3 fatty acids in the synthesis of complex PUFAs, such as docosahexaenoic acid, eicosapentaenoic acid, and anti-inflammatory prostaglandins is well-noted and thought to contribute to the reduction of pathologies associated with chronic disease, including metabolic syndrome. The challenge is that the conversion of $\alpha$-linolenic acid into these anti-inflammatory lipids is very limited in people; thus, increasing dietary intake, coupled with counseling to reduce the negative dietary features described earlier, is a popular strategy to improve metabolic health in obesity. N-3 PUFAs directly interact with G-protein coupled receptor (GPR) 120 to generate an intracellular signaling complex that inhibits multiple inflammatory pathways, such as NF- $\kappa \mathrm{B}$ and activated c-Jun Nterminal kinase, which are downstream of TLR and cytokine receptors (145). This effect is not limited to macrophage signaling and shifting the profile toward a resolving M2 phenotype; these healthy long-chain fatty acids also signal through GPR120 on adipocytes to reduce inflammation and improve insulin sensitivity, leading to less DAMP signaling from hypoxic, stressed adipocytes and decreased paracrine inflammatory effects on tissue-resident macrophages. In summary, healthy dietary features, such as fiber, n-3 PUFAs, and bioactive flavonoids can directly and indirectly drive the macrophage profile toward an M2 anti-inflammatory profile and a healthier state, even if the subject is obese (27). Diet can influence the balance of M1 and M2 macrophages in adipose both directly, by modifying the burden of DAMP/PAMP signaling and indirectly by influencing insulin sensitivity and tissue function of adipocytes and vascular cells in adipose. Therapeutic strategies that capitalize on dietary mechanisms are in development, including synthetic GPR120 ligands, probiotics, and synbiotics to improve intestinal barrier function, as methods to improve health in obese persons $(70,138)$.

\section{IMPACTS OF NON-ALCOHOLIC FATTY LIVER DISEASE ON ADIPOSE MACROPHAGE TYPES}

MHO individuals' liver composition and inflammatory signaling moderate the anti-inflammatory profile of their peripheral tissues. Obesity-related nutrient overload incites spillover of free fatty acids from AT that are taken up by the liver through the portal vein. Accordingly, increased visceral adipose accumulation corresponds with liver triglyceride accumulation. The severity of non-alcoholic fatty liver disease and nonalcoholic steatohepatitis has been shown to correspond with an expression of inflammatory genes in AT (146). Increased 
pro- and anti-inflammatory macrophage infiltration in visceral adipose was observed in obese patients with non-alcoholic steatohepatitis (146). MHO individuals demonstrate less liver triglyceride accumulation and liver fibrosis and overall improved liver function compared with MUO individuals (147, 148). Decreased liver fibrosis corresponded with fewer omental AT macrophages in obese humans, as macrophage accumulation decreased with decreasing fibro-inflammation indexes (149). Adiponectin, an adipokine that promotes AT lipid storage, lipid oxidation, and downstream anti-inflammatory signaling, is increased in $\mathrm{MHO}$ compared with MUO, providing another physiologic mechanism for MHO individuals' decreased liver triglyceride accumulation (150-152). Adiponectin has also been shown to correlate with insulin resistance in obese female people (153). Decreased liver triglyceride accumulation and fibrosis, along with increased effectiveness of anti-inflammatory signaling from the liver, correspond with reduced macrophage accumulation in $\mathrm{MHO}$ and allow for improved adipose storage and sustained AT glucose uptake.

\section{PARACRINE ADIPOSE EFFECTS ON THE CARDIOVASCULAR SYSTEM}

In addition to their decreased risk of all-cause mortality, $\mathrm{MHO}$ individuals experience a decreased risk of heart failure even compared with metabolically unhealthy lean individuals (154). The interactions between MHO individuals' AT and their cardiovascular system explain the observed cardiometabolic outcomes.

The AT perivascular and epicardial fat depots are in direct proximity to cardiovascular tissue and interact positively in a paracrine fashion with the myocardium and vasculature in $\mathrm{MHO}$ persons. Perivascular AT, located around the large arteries, produces nitric oxide and secretes adipocyte-derived relaxing factors and other adipokines that relax vascular smooth muscle cells and are able to go into microcirculation (155). As perivascular adipose maintains vascular bed homeostasis, it controls the effects of insulin on microcirculatory systems in metabolic tissues. For instance, perivascular adipose successfully facilitates insulin-mediated vasoreactivity and glucose uptake in skeletal muscle (156). Interestingly, loss of perivascular AT in lipoatrophic mice (A-ZIP/F1) enhances the contractile responses of blood vessels, which results in hypertension (157). In instances of pathological perivascular dysfunction, the perivascular AT release of adipocyte-derived relaxing factors diminishes, whereas its release of pro-inflammatory cytokines, including IL-6, tumor necrosis factor-alpha, and MCP-1, increases, and a negative cycle of perfusion and AT dysfunction perpetuates as described earlier. This directly impacts endothelial and vascular smooth muscle cells and incites vascular inflammation (155). Pro-inflammatory perivascular AT signaling is initiated by decreased nitric oxide production, increased reactive oxygen species, and pro-inflammatory cytokines released by the dysfunctional endothelium, vascular smooth muscle cells, or vascular macrophages (155). In MUO individuals, dysfunctional perivascular AT alterations stem from adipocyte hypertrophy, hypoxia, oxidative stress, and pro-inflammatory macrophage infiltration $(158,159)$. These data suggest that MHO perivascular AT successfully facilitates glucose uptake while promoting antiinflammatory macrophage accumulation.

Like perivascular AT, interactions between healthy epicardial $\mathrm{AT}$ and the myocardium mitigate pro-inflammatory signaling in $\mathrm{MHO}$ individuals. Epicardial AT, located between the myocardium and visceral pericardium, acts as an energy source for the myocardium, as epicardial adipose has a higher capacity for uptake and release of free fatty acids and a lower rate of glucose utilization than other visceral depots (160). Given its ability to take up free fatty acids, epicardial adipose is thought to act as a buffer for the myocardium against lipotoxicity $(160,161)$. However, in pathological settings, the epicardial adipose may provide excess free fatty acids associated with myocardial steatosis and systemic insulin resistance (162). Insulin resistance and $\mathrm{T} 2 \mathrm{D}$ are associated with increased MCP-1 expression in epicardial adipose, and peri-coronary adipose displays increased M1 macrophage infiltration compared with other regions distal to the coronaries $(163,164)$. The importance of whole-body health highlights that peri-coronary epicardial adipose inflammation may influence vascular function negatively as well as positively (163). In unhealthy obese states, hypoxic perivascular adipose transports macrophages that may carry oxidized cholesterol from systemic circulation to epicardial adipose through the neovascularized vasa vasorum $(165,166)$. Local epicardial AT inflammation also stems from dysregulated miRNA expression. Patients with coronary artery disease demonstrate increased miR-103-3b upregulation, which is a potential modulator of the pro-inflammatory cytokine CCL13 (167). Insulin resistance and T2D are characterized by changes in miRNAs, including miR-29a and miR-143, which regulate AT browning and inflammation (168). Importantly, miR-29a has been associated with myocardial fibrosis, whereas miR-143 is a biomarker of vascular smooth muscle cell activation that is linked to atherosclerosis and hypertension $(169,170)$. Adipose acts as a local renin-angiotensin system by producing angiotensinogen, a precursor to angiotensin II (171). The hypertension medication telmisartan-an angiotensin II type 1 receptor blocker and $\operatorname{PPAR} \gamma$ agonist-improved insulin resistance while decreasing M1 and increasing M2 macrophage gene expressions in visceral adipose from high-fat diet-fed mice (171). These data suggest that a hypertensive MUO person who has more M1 macrophages recruited into their adipose, when treated with telmisartan, may experience a shift in their adipose macrophage profile and a reduction in local inflammation. While epicardial AT function protects $\mathrm{MHO}$ individuals from lipotoxicity and maintains the anti-inflammatory immune cell profile, more work is needed to understand the crosstalk between epicardial adipose miRNAs, the cardiovascular system, and their relationship to health and disease.

\section{DISCUSSION}

In this review, we discuss how macrophage phenotypes drive adipose health in $\mathrm{MHO}$ and MUO persons, as these immune 
cells affect the local AT niche and are heavily influenced by diet and systemic health characteristics (Figure 1). Improved white adipose function in conjunction with the consumption of $n-3$ PUFAs, polyphenols, and fiber results in anti-inflammatory M2 macrophage programming in MHO. Functional white adipose adipogenesis, increased tissue vascularization, ECM turnover, and downstream anti-inflammatory signaling in combination with consumption of the dietary components mentioned earlier propagate M2 maintenance and proliferation while abating harmful pro-inflammatory M1 macrophage recruitment. Gut mucosal barrier integrity, functional liver-adipose, and cardiovascular system-adipose cross talk parallel the effects of diet by decreasing MHO AT pro-inflammatory signaling and maintaining insulin sensitivity. Alternatively, increased dietary consumption of saturated fat, cholesterols, trans fat, and fructose incites pro-inflammatory adipose macrophage recruitment in MUO adipose, which inhibits adipogenesis. Consumption of these dietary components, in conjunction with dysfunctional adipogenesis, results in augmented adipocyte hypertrophy. This, combined with decreased angiogenic signals, disrupted ECM turnover, and downstream pro-inflammatory cytokine secretion, stimulates further pro-inflammatory M1 macrophage recruitment. Impaired gut mucosal barrier integrity in the MUO drives multi-organ inflammation. This results in dysfunctional adipose-liver and adipose-cardiovascular system cross talk, which concurrently promote pro-inflammatory M1 macrophage recruitment in MUO adipose. Once M1 macrophages enter the tissue, they secrete additional pro-inflammatory cytokines that recruit more M1 macrophages. This vicious cycle of inflammation and perpetuation of unhealthy AT, further expansion, and greater multisystemic dysfunction characterizes MUO individuals.

Clearing M1 macrophages from unhealthy adipose may reestablish metabolic health. Obesity incites senescent cell accumulation in AT and M1 macrophage recruitment, and pharmacological senescent cell clearing agents have effectively

\section{REFERENCES}

1. World Health Organization. Obesity and Overweight. (2003). Available online at: https://www.who.int/news-room/fact-sheets/detail/obesity-andoverweight

2. Engin A. The definition and prevalence of obesity and metabolic syndrome. Adv Exp Med Biol. (2017) 960:1-17. doi: 10.1007/978-3-319-48382-5_1

3. Renehan AG, Tyson M, Egger M, Heller RF, Zwahlen M. Bodymass index and incidence of cancer: a systematic review and metaanalysis of prospective observational studies. Lancet. (2008) 371:569-78. doi: 10.1016/S0140-6736(08)60269-X

4. Saklayen MG. The global epidemic of the metabolic syndrome. Curr Hypertension Rep. (2018) 20:12. doi: 10.1007/s11906-018-0812-Z

5. Mann T, Tomiyama AJ, Westling E, Lew AM, Samuels B, Chatman J. Medicare's search for effective obesity treatments: diets are not the answer. Am Psychol. (2007) 62:220. doi: 10.1037/0003-066X.62.3.220

6. Primeau V, Coderre L, Karelis A, Brochu M, Lavoie M, Messier $\mathrm{V}$, et al. Characterizing the profile of obese patients who are metabolically healthy. Int J Obes. (2011) 35:971-81. doi: 10.1038/ijo.201 0.216

7. Blüher M. Metabolically healthy obesity. Endocr Rev. (2020) 41:bnaa004. doi: $10.1210 /$ endrev/bnaa004 reduced macrophage accumulation and pro-inflammatory signaling while restoring metabolic function in obese mice and people (172-174). Calcium/calmodulin-dependent protein kinases (CaMKs) play roles in myocardial ischemia/reperfusion injury, regulating food intake and energy expenditure. Activation of CaMK II $\delta$ in cardiomyocytes prompted pro-inflammatory macrophage recruitment and associated NF- $\mathrm{\kappa B}$ signaling that results in fibrosis and myocardial dysfunction (175). Loss of CaMK kinase II (CaMKK2) reduced AT M1 macrophagederived NF- $\mathrm{KB}$ signaling caused by a high-fat diet, highlighting an important function for CaMKK2 in controlling diet-induced adipose M1 macrophage inflammation (176). For example, treatment with a CAMKK2 inhibitor, tilianin, decreased proinflammatory signaling in cardiomyocytes (177). The use of CaMKK2 inhibitors in MUO may reduce AT inflammation, although more research is needed to determine how CaMK inhibition impacts AT immune cell populations over time.

As obesity rates continue to rise and weight-loss interventions prove largely unsuccessful, understanding how to mediate the vicious AT macrophage cycle in MUO individuals is imperative. Although long-term obesity ultimately increases the risks of multisystem adverse events, breaking the proinflammatory macrophage cycle will potentially shift MUO individuals to $\mathrm{MHO}$ and reduce current health burdens.

\section{AUTHOR CONTRIBUTIONS}

All authors listed have made a substantial, direct and intellectual contribution to the work, and approved it for publication.

\section{FUNDING}

The funding source for this work was the National Institutes of Health, National Heart, Lung, and Blood Institute. The grant number to be listed as R01HL142930.

8. Phillips CM. Metabolically healthy obesity: definitions, determinants and clinical implications. Rev Endocr Metab Disord. (2013) 14:219-27. doi: 10.1007/s11154-013-9 252-x

9. Durward C, Hartman TJ, Nickols-Richardson SM. All-cause mortality risk of metabolically healthy obese individuals in NHANES III. J Obes. (2012) 2012:460321. doi: 10.1155/2012/460321

10. National Cholesterol Education Program (NCEP) Expert Panel on Detection, Evaluation, and Treatment of High Blood Cholesterol in Adults (Adult Treatment Panel III). Third report of the National Cholesterol Education Program (NCEP) expert panel on detection, evaluation, and treatment of high blood cholesterol in adults (Adult Treatment Panel III) final report. Circulation. (2002) 106:3143-421.

11. Lavie CJ, Laddu D, Arena R, Ortega FB, Alpert MA, Kushner RF. Healthy weight and obesity prevention: JACC health promotion series. J Am Coll Cardiol. (2018) 72:1506-31. doi: 10.1016/j.jacc.2018.08.1037

12. Caleyachetty R, Thomas GN, Toulis KA, Mohammed N, Gokhale $\mathrm{KM}$, Balachandran $\mathrm{K}$, et al. Metabolically healthy obese and incident cardiovascular disease events among 3.5 million men and women. J Am Coll Cardiol. (2017) 70:1429-37. doi: 10.1016/j.jacc.2017.07.763

13. Zheng R, Zhou D, Zhu Y. The long-term prognosis of cardiovascular disease and all-cause mortality for metabolically healthy obesity: a systematic review 
and meta-analysis. J Epidemiol Community Health. (2016) 70:1024-31. doi: 10.1136/jech-2015-206948

14. Wronska A, Kmiec Z. Structural and biochemical characteristics of various white adipose tissue depots. Acta Physiol. (2012) 205:194-208. doi: 10.1111/j.1748-1716.2012.02409.x

15. Elffers TW, de Mutsert R, Lamb HJ, de Roos A, Willems van Dijk K, Rosendaal FR, et al. Body fat distribution, in particular visceral fat, is associated with cardiometabolic risk factors in obese women. PLoS ONE. (2017) 12:e0185403. doi: 10.1371/journal.pone.0185403

16. Park K, Rhee B, Lee K, Kim S, Lee H, Koh C-S, et al. Intra-abdominal fat is associated with decreased insulin sensitivity in healthy young men. Metabolism. (1991) 40:600-3. doi: 10.1016/0026-0495(91)90050-7

17. McLaughlin T, Lamendola C, Liu A, Abbasi F. Preferential fat deposition in subcutaneous vs. visceral depots is associated with insulin sensitivity. J Clin Endocrinol Metab. (2011) 96:E1756-60. doi: 10.1210/jc.2011-0615

18. Foster MT, Softic S, Caldwell J, Kohli R, Annette D, Seeley RJ. Subcutaneous adipose tissue transplantation in diet-induced obese mice attenuates metabolic dysregulation while removal exacerbates it. Physiol Rep. (2013) 1:e00015. doi: 10.1002/phy2.15

19. Kahn CR, Wang G, Lee KY. Altered adipose tissue and adipocyte function in the pathogenesis of metabolic syndrome. JClin Invest. (2019) 129:3990-4000. doi: 10.1172/JCI129187

20. Gustafson B, Gogg S, Hedjazifar S, Jenndahl L, Hammarstedt A, Smith U. Inflammation and impaired adipogenesis in hypertrophic obesity in man. Am J Physiol Endocrinol Metab. (2009) 297:E999-1003. doi: 10.1152/ajpendo.00377.2009

21. Adamczak M, Wiecek A. The adipose tissue as an endocrine organ. Semin Nephrol. (2013) 33:2-13. doi: 10.1016/j.semnephrol.2012.12.008

22. Atri C, Guerfali FZ, Laouini D. Role of human macrophage polarization in inflammation during infectious diseases. Int J Mol Sci. (2018) 19:1801. doi: 10.3390/ijms19061801

23. Russo L, Lumeng CN. Properties and functions of adipose tissue macrophages in obesity. Immunology. (2018) 155:407-17. doi: $10.1111 / \mathrm{imm} .13002$

24. Thomas D, Apovian C. Macrophage functions in lean and obese adipose tissue. Metabolism. (2017) 72:120-43. doi: 10.1016/j.metabol.2017.04.005

25. Weisberg SP, McCann D, Desai M, Rosenbaum M, Leibel RL, Ferrante AW. Obesity is associated with macrophage accumulation in adipose tissue. J Clin Invest. (2003) 112:1796-808. doi: 10.1172/JCI200319246

26. Xu H, Barnes GT, Yang Q, Tan G, Yang D, Chou CJ, et al. Chronic inflammation in fat plays a crucial role in the development of obesity-related insulin resistance. J Clin Invest. (2003) 112:1821-30. doi: 10.1172/JCI200319451

27. Lumeng CN, Bodzin JL, Saltiel AR. Obesity induces a phenotypic switch in adipose tissue macrophage polarization. J Clin Invest. (2007) 117:175-84. doi: $10.1172 /$ JCI29881

28. McLaughlin T, Ackerman SE, Shen L, Engleman E. Role of innate and adaptive immunity in obesity-associated metabolic disease. J Clin Invest. (2017) 127:5-13. doi: 10.1172/JCI88876

29. Lumeng CN, DelProposto JB, Westcott DJ, Saltiel AR. Phenotypic switching of adipose tissue macrophages with obesity is generated by spatiotemporal differences in macrophage subtypes. Diabetes. (2008) 57:3239-46. doi: 10.2337/db08-0872

30. Caslin HL, Bhanot M, Bolus WR, Hasty AH. Adipose tissue macrophages: Unique polarization and bioenergetics in obesity. Immunol Rev. (2020) 295:101-13. doi: $10.1111 /$ imr.12853

31. O'Neill LA, Kishton RJ, Rathmell J. A guide to immunometabolism for immunologists. Nat Rev Immunol. (2016) 16:553. doi: 10.1038/nri.2016.70

32. Catrysse L, van Loo G. Adipose tissue macrophages and their polarization in health and obesity. Cell Immunol. (2018) 330:114-9. doi: 10.1016/j.cellimm.2018.03.001

33. Hou J, Shi J, Chen L, Lv Z, Chen X, Cao H, et al. M2 macrophages promote myofibroblast differentiation of LR-MSCs and are associated with pulmonary fibrogenesis. Cell Commun Signal. (2018) 16:1-14. doi: $10.1186 /$ s12964-018-0300-8

34. Kavanagh K, Davis AT, Peters DE, LeGrand AC, Bharadwaj MS, Molina AJ. Regulators of mitochondrial quality control differ in subcutaneous fat of metabolically healthy and unhealthy obese monkeys. Obesity. (2017) 25:689-96. doi: 10.1002/oby.21762

35. Ni Y, Ni L, Zhuge F, Xu L, Fu Z, Ota T. Adipose tissue macrophage phenotypes and characteristics: the key to insulin resistance in obesity and metabolic disorders. Obesity. (2020) 28:225-34. doi: 10.1002/oby.22674

36. Coats BR, Schoenfelt KQ, Barbosa-Lorenzi VC, Peris E, Cui C, Hoffman A, et al. Metabolically activated adipose tissue macrophages perform detrimental and beneficial functions during diet-induced obesity. Cell Rep. (2017) 20:3149-61. doi: 10.1016/j.celrep.2017.08.096

37. Miyachi Y, Tsuchiya K, Shiba K, Mori K, Komiya C, Ogasawara N, et al. A reduced M1-like/M2-like ratio of macrophages in healthy adipose tissue expansion during SGLT2 inhibition. Sci Rep. (2018) 8:1-13. doi: 10.1038/s41598-018-34305-x

38. Kang K, Reilly SM, Karabacak V, Gangl MR, Fitzgerald K, Hatano B, et al. Adipocyte-derived Th2 cytokines and myeloid PPAR $\delta$ regulate macrophage polarization and insulin sensitivity. Cell Metab. (2008) 7:485-95. doi: 10.1016/j.cmet.2008.04.002

39. Sugii S, Olson P, Sears DD, Saberi M, Atkins AR, Barish GD, et al. PPAR $\gamma$ activation in adipocytes is sufficient for systemic insulin sensitization. Proc Natl Acad Sci USA. (2009) 106:22504-9. doi: 10.1073/pnas.0912487106

40. Macias-Gonzalez M, Moreno-Santos I, García-Almeida J, Tinahones F, Garcia-Fuentes E. PPAR $\gamma 2$ protects against obesity by means of a mechanism that mediates insulin resistance. Eur J Clin Invest. (2009) 39:972-9. doi: $10.1111 / j .1365-2362.2009 .02198 . x$

41. Garcia-Fuentes E, Murri M, Garrido-Sanchez L, Garcia-Serrano S, GarcíaAlmeida JM, Moreno-Santos I, et al. PPAR $\gamma$ expression after a high-fat meal is associated with plasma superoxide dismutase activity in morbidly obese persons. Obesity. (2010) 18:952-8. doi: 10.1038/oby.2009.314

42. Odegaard JI, Ricardo-Gonzalez RR, Goforth MH, Morel CR, Subramanian $\mathrm{V}$, Mukundan L, et al. Macrophage-specific PPAR $\gamma$ controls alternative activation and improves insulin resistance. Nature. (2007) 447:1116-20. doi: 10.1038 /nature05894

43. Moreno-Indias I, Tinahones FJ. Impaired adipose tissue expandability and lipogenic capacities as ones of the main causes of metabolic disorders. $J$ Diabetes Res. (2015) 2015:970375. doi: 10.1155/2015/970375

44. Lacasa D, Taleb S, Keophiphath M, Miranville A, Clement K. Macrophage-secreted factors impair human adipogenesis: involvement of proinflammatory state in preadipocytes. Endocrinology. (2007) 148:868-77. doi: 10.1210/en.2006-0687

45. Sorisky A, Molgat AS, Gagnon A. Macrophage-induced adipose tissue dysfunction and the preadipocyte: should I stay (and differentiate) or should I go? Adv Nutr. (2013) 4:67-75. doi: 10.3945/an.112.003020

46. Nawaz A, Aminuddin A, Kado T, Takikawa A, Yamamoto S, Tsuneyama K, et al. CD206+ M2-like macrophages regulate systemic glucose metabolism by inhibiting proliferation of adipocyte progenitors. Nat Commun. (2017) 8:1-16. doi: 10.1038/s41467-017-00231-1

47. Martinez-Santibañez G, Nien-Kai Lumeng C. Macrophages and the regulation of adipose tissue remodeling. Annu Rev Nutr. (2014) 34:57-76. doi: 10.1146/annurev-nutr-071812-161113

48. McLaughlin T, Sherman A, Tsao P, Gonzalez O, Yee G, Lamendola C, et al. Enhanced proportion of small adipose cells in insulin-resistant vs insulinsensitive obese individuals implicates impaired adipogenesis. Diabetologia. (2007) 50:1707-15. doi: 10.1007/s00125-007-0708-y

49. Almuraikhy S, Kafienah W, Bashah M, Diboun I, Jaganjac M, AlKhelaifi F, et al. Interleukin-6 induces impairment in human subcutaneous adipogenesis in obesity-associated insulin resistance. Diabetologia. (2016) 59:2406-16. doi: 10.1007/s00125-016-4031-3

50. Yang X, Jansson P-A, Nagaev I, Jack MM, Carvalho E, Sunnerhagen KS, et al. Evidence of impaired adipogenesis in insulin resistance. Biochem Biophys Res Commun. (2004) 317:1045-51. doi: 10.1016/j.bbrc.2004.03.152

51. Park HT, Lee ES, Cheon YP, Lee DR, Yang KS, Kim YT, et al. The relationship between fat depot-specific preadipocyte differentiation and metabolic syndrome in obese women. Clin Endocrinol. (2012) 76:59-66. doi: $10.1111 / j .1365-2265.2011 .04141 . x$

52. Maryam A, Jae M, Nasun H, Christopher L, Annette R, Michael D. PPAR $\gamma$ signaling and metabolism: the good, the bad and the future. Nat Med. (2013) 19:557-66. doi: 10.1038/nm.3159 
53. Smith U, Kahn BB. Adipose tissue regulates insulin sensitivity: role of adipogenesis, de novo lipogenesis and novel lipids. J Intern Med. (2016) 280:465-75. doi: 10.1111/joim.12540

54. Vishvanath L, Gupta RK. Contribution of adipogenesis to healthy adipose tissue expansion in obesity. $J$ Clin Invest. (2019) 129:4022-31. doi: 10.1172/JCI12 9191

55. Hammarstedt A, Gogg S, Hedjazifar S, Nerstedt A, Smith U. Impaired adipogenesis and dysfunctional adipose tissue in human hypertrophic obesity. Physiol Rev. (2018) 98:1911-41. doi: 10.1152/physrev.00034.2017

56. Gómez-Serrano M, Camafeita E, García-Santos E, López JA, Rubio MA, Sánchez-Pernaute A, et al. Proteome-wide alterations on adipose tissue from obese patients as age-, diabetes-and gender-specific hallmarks. Sci Rep. (2016) 6:25756. doi: 10.1038/srep25756

57. Kursawe R, Eszlinger M, Narayan D, Liu T, Bazuine M, Cali AM, et al. Cellularity and adipogenic profile of the abdominal subcutaneous adipose tissue from obese adolescents: association with insulin resistance and hepatic steatosis. Diabetes. (2010) 59:2288-96. doi: 10.2337/db10-0113

58. Ma H, Li Y-n, Song L, Liu R, Li X, Shang Q, et al. Macrophages inhibit adipogenic differentiation of adipose tissue derived mesenchymal stem/stromal cells by producing pro-inflammatory cytokines. Cell Biosci. (2020) 10:1-12. doi: 10.1186/s13578-020-00450-y

59. Belligoli A, Compagnin C, Sanna M, Favaretto F, Fabris R, Busetto L, et al. Characterization of subcutaneous and omental adipose tissue in patients with obesity and with different degrees of glucose impairment. Sci Rep. (2019) 9:11333. doi: 10.1038/s41598-019-47719-y

60. Khan T, Muise ES, Iyengar P, Wang ZV, Chandalia M, Abate N, et al. Metabolic dysregulation and adipose tissue fibrosis: role of collagen VI. Mol Cell Biol. (2009) 29:1575-91. doi: 10.1128/MCB.01300-08

61. Carobbio S, Pellegrinelli V, Vidal-Puig A. Adipose tissue function and expandability as determinants of lipotoxicity and the metabolic syndrome. Adv Exp Med Biol. (2017) 960:161-96. doi: 10.1007/978-3-319-48382-5_7

62. Chouchani ET, Kajimura S. Metabolic adaptation and maladaptation in adipose tissue. Nat Metab. (2019) 1:189-200. doi: 10.1038/s42255-018-0021-8

63. Guzmán-Ruiz R, Tercero-Alcázar C, Rabanal-Ruiz Y, Díaz-Ruiz A, El Bekay $\mathrm{R}$, Rangel-Zuñiga OA, et al. Adipose tissue depot-specific intracellular and extracellular cues contributing to insulin resistance in obese individuals. FASEB J. (2020) 34:7520-39. doi: 10.1096/fj.201902703R

64. Datta R, Podolsky MJ, Atabai K. Fat fibrosis: friend or foe? JCI insight. (2018) 3:e122289. doi: 10.1172/jci.insight.122289

65. Ruiz-Ojeda FJ, Méndez-Gutiérrez A, Aguilera CM, Plaza-Díaz J. Extracellular matrix remodeling of adipose tissue in obesity and metabolic diseases. Int J Mol Sci. (2019) 20:4888. doi: 10.3390/ijms20194888

66. Sun K, Kusminski CM, Scherer PE. Adipose tissue remodeling and obesity. J Clin Invest. (2011) 121:2094-101. doi: 10.1172/JCI45887

67. Doulamis IP, Konstantopoulos P, Tzani A, Antoranz A, Minia A, Daskalopoulou A, et al. Visceral white adipose tissue and serum proteomic alternations in metabolically healthy obese patients undergoing bariatric surgery. Cytokine. (2019) 115:76-83. doi: 10.1016/j.cyto.2018.11.017

68. Bonnans C, Chou J, Werb Z. Remodelling the extracellular matrix in development and disease. Nat Rev Mol Cell Biol. (2014) 15:786-801. doi: $10.1038 / \mathrm{nrm} 3904$

69. Hopps E, Presti RL, Montana M, Noto D, Averna MR, Caimi G. Gelatinases and their tissue inhibitors in a group of subjects with metabolic syndrome. $J$ Invest Med. (2013) 61:978-83. doi: 10.2310/JIM.0b013e318294e9da

70. Oh DY, Talukdar S, Bae EJ, Imamura T, Morinaga H, Fan W, et al. GPR120 is an omega-3 fatty acid receptor mediating potent antiinflammatory and insulin-sensitizing effects. Cell. (2010) 142:687-98. doi: 10.1016/j.cell.2010.07.041

71. Fenech M, Gavrilovic J, Malcolm P, Toms A, Turner J. The role of metalloproteinases and their tissue inhibitors in adipose tissue remodelling and whole-body lipid distribution: a cross-sectional clinical study. Lancet. (2015) 385:S36. doi: 10.1016/S0140-6736(15)60351-8

72. Arcidiacono B, Chiefari E, Laria AE, Messineo S, Bilotta FL, Britti D, et al. Expression of matrix metalloproteinase-11 is increased under conditions of insulin resistance. World J Diabetes. (2017) 8:422. doi: 10.4239/wjd.v8.i9.422
73. Menghini R, Menini S, Amoruso R, Fiorentino L, Casagrande V, Marzano $\mathrm{V}$, et al. Tissue inhibitor of metalloproteinase 3 deficiency causes hepatic steatosis and adipose tissue inflammation in mice. Gastroenterology. (2009) 136:663-72.e4. doi: 10.1053/j.gastro.2008.10.079

74. Menghini R, Casagrande V, Menini S, Marino A, Marzano V, Hribal ML, et al. TIMP3 overexpression in macrophages protects from insulin resistance, adipose inflammation, and nonalcoholic fatty liver disease in mice. Diabetes. (2012) 61:454-62. doi: 10.2337/db11-0613

75. Pasarica M, Gowronska-Kozak B, Burk D, Remedios I, Hymel D, Gimble J, et al. Adipose tissue collagen VI in obesity. J Clin Endocrinol Metab. (2009) 94:5155-62. doi: 10.1210/jc.2009-0947

76. Spencer M, Yao-Borengasser A, Unal R, Rasouli N, Gurley CM, Zhu B, et al. Adipose tissue macrophages in insulin-resistant subjects are associated with collagen VI and fibrosis and demonstrate alternative activation. Am J Physiol Endocrinol Metab. (2010) 299:E1016-27. doi: 10.1152/ajpendo.00329.2010

77. Reggio S, Rouault C, Poitou C, Bichet JC, Prifti E, Bouillot JL, et al. Increased basement membrane components in adipose tissue during obesity: links with TGF $\beta$ and metabolic phenotypes. J Clin Endocrinol Metab. (2016) 101:2578-87. doi: 10.1210/jc.2015-4304

78. Weng X, Lin D, Huang JT, Stimson RH, Wasserman DH, Kang L. Collagen $24 \alpha 1$ is increased in insulin-resistant skeletal muscle and adipose tissue. Int J Mol Sci. (2020) 21:5738. doi: 10.3390/ijms21165738

79. Alba DL, Farooq JA, Lin MY, Schafer AL, Shepherd J, Koliwad SK. Subcutaneous fat fibrosis links obesity to insulin resistance in Chinese Americans. J Clin Endocrinol Metab. (2018) 103:3194-204. doi: 10.1210/jc.2017-02301

80. Liu LF, Kodama K, Wei K, Tolentino LL, Choi O, Engleman EG, et al. The receptor CD44 is associated with systemic insulin resistance and proinflammatory macrophages in human adipose tissue. Diabetologia. (2015) 58:1579-86. doi: 10.1007/s00125-015-3603-y

81. Meissburger B, Stachorski L, Röder E, Rudofsky G, Wolfrum C. Tissue inhibitor of matrix metalloproteinase 1 (TIMP1) controls adipogenesis in obesity in mice and in humans. Diabetologia. (2011) 54:1468-79. doi: 10.1007/s00125-011-2093-9

82. Chabot K, Gauthier M-S, Garneau P, Rabasa-Lhoret R. Evolution of subcutaneous adipose tissue fibrosis after bariatric surgery. Diabetes Metab. (2017) 43:125-33. doi: 10.1016/j.diabet.2016.10.004

83. Tran TT, Yamamoto Y, Gesta S, Kahn CR. Beneficial effects of subcutaneous fat transplantation on metabolism. Cell Metab. (2008) 7:41020. doi: 10.1016/j.cmet.2008.04.004

84. Wynn TA. Fibrotic disease and the TH 1/TH 2 paradigm. Nat Rev Immunol. (2004) 4:583-94. doi: 10.1038/nril412

85. Lorenzen J, Kumarswamy R, Dangwal S, Thum T. MicroRNAs in diabetes and diabetes-associated complications. RNA Biol. (2012) 9:820-7. doi: $10.4161 /$ rna.20162

86. Zhao H, Shang Q, Pan Z, Bai Y, Li Z, Zhang H, et al. Exosomes from adiposederived stem cells attenuate adipose inflammation and obesity through polarizing M2 macrophages and beiging in white adipose tissue. Diabetes. (2018) 67:235-47. doi: 10.2337/db17-0356

87. Pan Y, Hui X, Hoo RLC, Ye D, Chan CYC, Feng T, et al. Adipocyte-secreted exosomal microRNA-34a inhibits M2 macrophage polarization to promote obesity-induced adipose inflammation. J Clin Invest. (2019) 129:834-49. doi: $10.1172 / J C I 123069$

88. Li R, Shen Q, Wu N, He M, Liu N, Huang J, et al. MiR-145 improves macrophage-mediated inflammation through targeting Arf6. Endocrine. (2018) 60:73-82. doi: 10.1007/s12020-018-1521-8

89. Arderiu G, Peña E, Aledo R, Juan-Babot O, Crespo J, Vilahur G, et al. MicroRNA-145 regulates the differentiation of adipose stem cells toward microvascular endothelial cells and promotes angiogenesis. Circ Res. (2019) 125:74-89. doi: 10.1161/CIRCRESAHA.118.314290

90. Ferrante SC, Nadler EP, Pillai DK, Hubal MJ, Wang Z, Wang JM, et al. Adipocyte-derived exosomal miRNAs: a novel mechanism for obesityrelated disease. Pediatr Res. (2015) 77:447-54. doi: 10.1038/pr.2014.202

91. Zhao B, Li H, Liu J, Han P, Zhang C, Bai H, et al. MicroRNA-23b targets Ras GTPase-activating protein $\mathrm{SH} 3$ domain-binding protein 2 to alleviate fibrosis and albuminuria in diabetic nephropathy. J Am Soc Nephrol. (2016) 27:2597-608. doi: 10.1681/ASN.2015030300 
92. Levy BI, Schiffrin EL, Mourad J-J, Agostini D, Vicaut E, Safar $\mathrm{ME}$, et al. Impaired tissue perfusion: a pathology common to hypertension, obesity, and diabetes mellitus. Circulation. (2008) 118:968-76. doi: 10.1161/CIRCULATIONAHA.107. 763730

93. Lee YS, Kim J-w, Osborne O, Sasik R, Schenk S, Chen A, et al. Increased adipocyte O2 consumption triggers HIF-1 $\alpha$, causing inflammation and insulin resistance in obesity. Cell. (2014) 157:1339-52. doi: 10.1016/j.cell.2014.05.012

94. Crewe C, An YA, Scherer PE. The ominous triad of adipose tissue dysfunction: inflammation, fibrosis, and impaired angiogenesis. J Clin Invest. (2017) 127:74-82. doi: 10.1172/JCI88883

95. Gealekman O, Guseva N, Hartigan C, Apotheker S, Gorgoglione M, Gurav K, et al. Depot-specific differences and insufficient subcutaneous adipose tissue angiogenesis in human obesity. Circulation. (2011) 123:186-94. doi: 10.1161/CIRCULATIONAHA.110.97 0145

96. Czernichow S, Greenfield JR, Galan P, Bastard J-P, Charnaux N, Samaras K, et al. Microvascular dysfunction in healthy insulinsensitive overweight individuals. J Hypertension. (2010) 28:325-32. doi: 10.1097/HJH.0b013e328333d1fc

97. Ortega FB, Lee D-c, Katzmarzyk PT, Ruiz JR, Sui X, Church TS, et al. The intriguing metabolically healthy but obese phenotype: cardiovascular prognosis and role of fitness. Eur Heart J. (2013) 34:389-97. doi: 10.1093/eurheartj/ehs174

98. Machado MV, Vieira AB, da Conceição FG, Nascimento AR, da Nóbrega ACL, Tibirica E. Exercise training dose differentially alters muscle and heart capillary density and metabolic functions in an obese rat with metabolic syndrome. Exp Physiol. (2017) 102:1716-28. doi: 10.1113/EP086416

99. Elias I, Franckhauser S, Ferré T, Vilà L, Tafuro S, Muñoz S, et al. Adipose tissue overexpression of vascular endothelial growth factor protects against diet-induced obesity and insulin resistance. Diabetes. (2012) 61:1801-13. doi: $10.2337 / \mathrm{db} 11-0832$

100. Robciuc MR, Kivelä R, Williams IM, de Boer JF, van Dijk TH, Elamaa H, et al. VEGFB/VEGFR1-induced expansion of adipose vasculature counteracts obesity and related metabolic complications. Cell Metab. (2016) 23:712-24. doi: 10.1016/j.cmet.2016.03.004

101. Sung H-K, Doh K-O, Son JE, Park JG, Bae Y, Choi S, et al. Adipose vascular endothelial growth factor regulates metabolic homeostasis through angiogenesis. Cell Metab. (2013) 17:61-72. doi: 10.1016/j.cmet.2012.12.010

102. Kolahdouzi S, Talebi-Garakani E, Hamidian G, Safarzade A. Exercise training prevents high-fat diet-induced adipose tissue remodeling by promoting capillary density and macrophage polarization. Life Sci. (2019) 220:32-43. doi: 10.1016/j.lfs.2019.01.037

103. Tang W, Zeve D, Suh JM, Bosnakovski D, Kyba M, Hammer RE, et al. White fat progenitor cells reside in the adipose vasculature. Science. (2008) 322:583-6. doi: 10.1126/science.1156232

104. Drolet R, Richard C, Sniderman A, Mailloux J, Fortier M, Huot C, et al. Hypertrophy and hyperplasia of abdominal adipose tissues in women. Int J Obes. (2008) 32:283-91. doi: 10.1038/sj.ijo.0803708

105. Pasarica M, Sereda OR, Redman LM, Albarado DC, Hymel DT, Roan LE, et al. Reduced adipose tissue oxygenation in human obesity: evidence for rarefaction, macrophage chemotaxis, and inflammation without an angiogenic response. Diabetes. (2009) 58:718-25. doi: 10.2337/db08-1098

106. Tinahones FJ, Coín-Aragüez L, Mayas MD, Garcia-Fuentes E, Hurtado-delPozo C, Vendrell J, et al. Obesity-associated insulin resistance is correlated to adipose tissue vascular endothelial growth factors and metalloproteinase levels. BMC Physiol. (2012) 12:4. doi: 10.1186/1472-6793-12-4

107. Xu F, Burk D, Gao Z, Yin J, Zhang X, Weng J, et al. Angiogenic deficiency and adipose tissue dysfunction are associated with macrophage malfunction in SIRT1 $1^{-/}$mice. Endocrinology. (2012) 153:1706-16. doi: 10.1210/en.2011-1667

108. Pang C, Gao Z, Yin J, Zhang J, Jia W, Ye J. Macrophage infiltration into adipose tissue may promote angiogenesis for adipose tissue remodeling in obesity. Am J Physiol Endocrinol Metab. (2008) 295:E313-22. doi: 10.1152/ajpendo.90296.2008

109. Jetten N, Verbruggen S, Gijbels MJ, Post MJ, De Winther MP, Donners MM. Anti-inflammatory M2, but not pro-inflammatory M1 macrophages promote angiogenesis in vivo. Angiogenesis. (2014) 17:109-18. doi: 10.1007/s10456-013-9381-6

110. Zajac E, Schweighofer B, Kupriyanova TA, Juncker-Jensen A, Minder P, Quigley JP, et al. Angiogenic capacity of M1-and M2-polarized macrophages is determined by the levels of TIMP-1 complexed with their secreted proMMP-9. Blood. (2013) 122:4054-67. doi: 10.1182/blood-2013-05-501494

111. Gong T, Liu L, Jiang W, Zhou R. DAMP-sensing receptors in sterile inflammation and inflammatory diseases. Nat Rev Immunol. (2020) 20:95112. doi: 10.1038/s41577-019-0215-7

112. Li C, Xu MM, Wang K, Adler AJ, Vella AT, Zhou B. Macrophage polarization and meta-inflammation. Transl Res. (2018) 191:29-44. doi: 10.1016/j.trsl.2017.1 0.004

113. Amar J, Burcelin R, Ruidavets JB, Cani PD, Fauvel J, Alessi MC, et al. Energy intake is associated with endotoxemia in apparently healthy men. Am J Clin Nutr. (2008) 87:1219-23. doi: 10.1093/ajcn/87.5.1219

114. Cani PD, Amar J, Iglesias MA, Poggi M, Knauf C, Bastelica D, et al. Metabolic endotoxemia initiates obesity and insulin resistance. Diabetes. (2007) 56:1761-72. doi: 10.2337/db06-1491

115. Cani PD, Bibiloni R, Knauf C, Waget A, Neyrinck AM, Delzenne NM, et al. Changes in gut microbiota control metabolic endotoxemia-induced inflammation in high-fat diet-induced obesity and diabetes in mice. Diabetes. (2008) 57:1470-81. doi: 10.2337/db07-1403

116. Baena M, Sanguesa G, Davalos A, Latasa MJ, Sala-Vila A, Sanchez RM, et al. Fructose, but not glucose, impairs insulin signaling in the three major insulin-sensitive tissues. Sci Rep. (2016) 6:26149. doi: 10.1038/srep26149

117. Bergheim I, Weber S, Vos M, Kramer S, Volynets V, Kaserouni $\mathrm{S}$, et al. Antibiotics protect against fructose-induced hepatic lipid accumulation in mice: role of endotoxin. J Hepatol. (2008) 48:983-92. doi: 10.1016/j.jhep.2008.01.035

118. Kavanagh K, Wylie AT, Tucker KL, Hamp TJ, Gharaibeh RZ, Fodor AA, et al. Dietary fructose induces endotoxemia and hepatic injury in calorically controlled primates. Am J Clin Nutr. (2013) 98:349-57. doi: 10.3945/ajcn.112.057331

119. Spruss A, Kanuri G, Wagnerberger S, Haub S, Bischoff SC, Bergheim I. Tolllike receptor 4 is involved in the development of fructose-induced hepatic steatosis in mice. Hepatology. (2009) 50:1094-104. doi: 10.1002/hep.23122

120. Stanhope KL, Schwarz JM, Keim NL, Griffen SC, Bremer AA, Graham $\mathrm{JL}$, et al. Consuming fructose-sweetened, not glucose-sweetened, beverages increases visceral adiposity and lipids and decreases insulin sensitivity in overweight/obese humans. J Clin Invest. (2009) 119:1322-34. doi: $10.1172 /$ JCI37385

121. Sobrecases H, Lê K-A, Bortolotti M, Schneiter P, Ith M, Kreis R, et al. Effects of short-term overfeeding with fructose, fat and fructose plus fat on plasma and hepatic lipids in healthy men. Diabetes Metab. (2010) 36:244-6. doi: 10.1016/j.diabet.2010.03.003

122. Anhe FF, Jensen BAH, Varin TV, Servant F, Van Blerk S, Richard D, et al. Type 2 diabetes influences bacterial tissue compartmentalisation in human obesity. Nat Metab. (2020) 2:233-42. doi: 10.1038/s42255-020-0178-9

123. Jensen BA, Marette A. Microbial translocation in type 2 diabetes: when bacterial invaders overcome host defence in human obesity. Gut. (2020) 69:1724-6. doi: 10.1136/gutjnl-2020-321288

124. Massier L, Chakaroun R, Tabei S, Crane A, Didt KD, Fallmann $\mathrm{J}$, et al. Adipose tissue derived bacteria are associated with inflammation in obesity and type 2 diabetes. Gut. (2020) 69:1796-806. doi: 10.1136/gutjnl-2019-320118

125. Wu GD, Chen J, Hoffmann C, Bittinger K, Chen YY, Keilbaugh SA, et al. Linking long-term dietary patterns with gut microbial enterotypes. Science. (2011) 334:105-8. doi: 10.1126/science.1208344

126. Horne JE, Brockwell DJ, Radford SE. Role of the lipid bilayer in outer membrane protein folding in Gram negative bacteria. J Biol Chem. (2020) 295:10340-67. doi: 10.1074/jbc.REV120.011473

127. Gonzalez F, Considine RV, Abdelhadi OA, Acton AJ. Saturated fat ingestion promotes lipopolysaccharide-mediated inflammation and insulin resistance in polycystic ovary syndrome. J Clin Endocrinol Metab. (2019) 104:934-46. doi: 10.1210/jc.2018-01143

128. Quintanilha BJ, Pinto Ferreira LR, Ferreira FM, Neto EC, Sampaio GR, Rogero MM. Circulating plasma microRNAs dysregulation and metabolic 
endotoxemia induced by a high-fat high-saturated diet. Clin Nutr. (2020) 39:554-62. doi: 10.1016/j.clnu.2019.02.042

129. Sanchez-Tapia M, Miller AW, Granados-Portillo O, Tovar AR, Torres N. The development of metabolic endotoxemia is dependent on the type of sweetener and the presence of saturated fat in the diet. Gut Microbes. (2020) 12:1801301. doi: 10.1080/19490976.2020.1801301

130. Estadella D, da Penha Oller do Nascimento CM, Oyama LM, Ribeiro EB, Damaso AR, de Piano A. Lipotoxicity: effects of dietary saturated and transfatty acids. Mediators Inflamm. (2013) 2013:137579. doi: 10.1155/2013/137579

131. Kavanagh K, Jones KL, Sawyer J, Kelley K, Carr JJ, Wagner JD, et al. Trans fat diet induces abdominal obesity and changes in insulin sensitivity in monkeys. Obesity (Silver Spring). (2007) 15:1675-84. doi: 10.1038/oby.2007.200

132. Russo L, Muir L, Geletka L, Delproposto J, Baker N, Flesher C, et al. Cholesterol 25-hydroxylase $(\mathrm{CH} 25 \mathrm{H})$ as a promoter of adipose tissue inflammation in obesity and diabetes. Mol Metab. (2020) 39:100983. doi: 10.1016/j.molmet.2020.100983

133. Hubler MJ, Kennedy AJ. Role of lipids in the metabolism and activation of immune cells. J Nutr Biochem. (2016) 34:1-7. doi: 10.1016/j.jnutbio.2015.11.002

134. Wang Y, Huang F. N-3 polyunsaturated fatty acids and inflammation in obesity: local effect and systemic benefit. BioMed Res Int. (2015) 2015:581469. doi: $10.1155 / 2015 / 581469$

135. Grant RW, Dixit VD. Adipose tissue as an immunological organ. Obesity. (2015) 23:512-8. doi: 10.1002/oby.21003

136. Ahola AJ, Lassenius MI, Forsblom C, Harjutsalo V, Lehto M, Groop PH. Dietary patterns reflecting healthy food choices are associated with lower serum LPS activity. Sci Rep. (2017) 7:6511. doi: 10.1038/s41598-017-06885-7

137. Dewulf EM, Cani PD, Claus SP, Fuentes S, Puylaert PG, Neyrinck AM, et al. Insight into the prebiotic concept: lessons from an exploratory, double blind intervention study with inulin-type fructans in obese women. Gut. (2013) 62:1112-21. doi: 10.1136/gutjnl-2012-303304

138. Krumbeck JA, Rasmussen HE, Hutkins RW, Clarke J, Shawron K, Keshavarzian A, et al. Probiotic Bifidobacterium strains and galactooligosaccharides improve intestinal barrier function in obese adults but show no synergism when used together as synbiotics. Microbiome. (2018) 6:121. doi: 10.1186/s40168-018-0494-4

139. Fardoun MM, Maaliki D, Halabi N, Iratni R, Bitto A, Baydoun E, et al. Flavonoids in adipose tissue inflammation and atherosclerosis: one arrow, two targets. Clin Sci (Lond). (2020) 134:1403-32. doi: 10.1042/CS20200356

140. Bolego C, Cignarella A, Staels B, Chinetti-Gbaguidi G. Macrophage function and polarization in cardiovascular disease: a role of estrogen signaling? Arterioscler Thromb Vasc Biol. (2013) 33:1127-34. doi: 10.1161/ATVBAHA.113.301328

141. Wang L, Zhao RP, Song XY, Wu WF. Targeting ERbeta in macrophage reduces crown-like structures in adipose tissue by inhibiting osteopontin and HIF-1alpha. Sci Rep. (2019) 9:15762. doi: 10.1038/s41598-019-52265-8

142. Steinberg FM, Guthrie NL, Villablanca AC, Kumar K, Murray MJ. Soy protein with isoflavones has favorable effects on endothelial function that are independent of lipid and antioxidant effects in healthy postmenopausal women. Am J Clin Nutr. (2003) 78:123-30. doi: 10.1093/ajcn/78.1.123

143. Yamagata K, Yamori Y. Inhibition of endothelial dysfunction by dietary flavonoids and preventive effects against cardiovascular disease. J Cardiovasc Pharmacol. (2020) 75:1-9. doi: 10.1097/FJC.0000000000000757

144. Brenner RR. Regulatory function of delta6 desaturate-key enzyme of polyunsaturated fatty acid synthesis. Adv Exp Med Biol. (1977) 83:85-101. doi: 10.1007/978-1-4684-3276-3_8

145. Trayhurn P, Denyer G. Mining microarray datasets in nutrition: expression of the GPR120 (n-3 fatty acid receptor/sensor) gene is down-regulated in human adipocytes by macrophage secretions. J Nutr Sci. (2012) 1:e3. doi: $10.1017 /$ jns. 2012.3

146. Du Plessis J, Van Pelt J, Korf H, Mathieu C, Van der Schueren B, Lannoo $\mathrm{M}$, et al. Association of adipose tissue inflammation with histologic severity of nonalcoholic fatty liver disease. Gastroenterology. (2015) 149:635-48. e14. doi: 10.1053/j.gastro.2015.05.044

147. Dobson R, Burgess MI, Sprung VS, Irwin A, Hamer M, Jones J, et al. Metabolically healthy and unhealthy obesity: differential effects on myocardial function according to metabolic syndrome, rather than obesity. Int J Obes. (2016) 40:153-61. doi: 10.1038/ijo.2015.151

148. Gutiérrez-Grobe Y, Juárez-Hernández E, Sánchez-Jiménez B, UribeRamos $M$, Ramos-Ostos $M$, Uribe $M$, et al. Less liver fibrosis in metabolically healthy compared with metabolically unhealthy obese patients with non-alcoholic fatty liver disease. Diabetes Metab. (2017) 43:332-7. doi: 10.1016/j.diabet.2017.02.007

149. Tordjman J, Poitou C, Hugol D, Bouillot J-L, Basdevant A, Bedossa P, et al. Association between omental adipose tissue macrophages and liver histopathology in morbid obesity: influence of glycemic status. J Hepatol. (2009) 51:354-62. doi: 10.1016/j.jhep.2009.02.031

150. Doumatey AP, Bentley AR, Zhou J, Huang H, Adeyemo A, Rotimi CN. Paradoxical hyperadiponectinemia is associated with the metabolically healthy obese (MHO) phenotype in African Americans. J Endocrinol Metab. (2012) 2:51. doi: 10.4021/jem95w

151. Ahl S, Guenther M, Zhao S, James R, Marks J, Szabo A, et al. Adiponectin levels differentiate metabolically healthy vs unhealthy among obese and nonobese white individuals. J Clin Endocrinol Metab. (2015) 100:4172-80. doi: 10.1210/jc.2015-2765

152. Duwaerts CC, Maher JJ. Macronutrients and the adipose-liver axis in obesity and fatty liver. Cell Mol Gastroenterol Hepatol. (2019) 7:749-61. doi: 10.1016/j.jcmgh.2019.02.001

153. Kang YE, Kim JM, Joung KH, Lee JH, You BR, Choi MJ, et al. The roles of adipokines, proinflammatory cytokines, and adipose tissue macrophages in obesity-associated insulin resistance in modest obesity and early metabolic dysfunction. PLoS ONE. (2016) 11:e0154003. doi: 10.1371/journal.pone. 0154003

154. Voulgari C, Tentolouris N, Dilaveris P, Tousoulis D, Katsilambros N, Stefanadis C. Increased heart failure risk in normal-weight people with metabolic syndrome compared with metabolically healthy obese individuals. J Am Coll Cardiol. (2011) 58:1343-50. doi: 10.1016/j.jacc.2011.04.047

155. Nosalski R, Guzik TJ. Perivascular adipose tissue inflammation in vascular disease. Br J Pharmacol. (2017) 174:3496-513. doi: 10.1111/bph.13705

156. Turaihi AH, Serné EH, Molthoff CF, Koning JJ, Knol J, Niessen $\mathrm{HW}$, et al. Perivascular adipose tissue controls insulin-stimulated perfusion, mitochondrial protein expression, and glucose uptake in muscle through adipomuscular arterioles. Diabetes. (2020) 69:603-13. doi: $10.2337 / \mathrm{db} 18-1066$

157. Takemori K, Gao Y-J, Ding L, Lu C, Su L-Y, An W-S, et al. Elevated blood pressure in transgenic lipoatrophic mice and altered vascular function. Hypertension. (2007) 49:365-72. doi: 10.1161/01.HYP.0000255576.16089.b9

158. Virdis A. Endothelial dysfunction in obesity: role of inflammation. High Blood Pressure Cardiovasc Prev. (2016) 23:83-5. doi: 10.1007/s40292-016-0133-8

159. Zhu X, Zhang H, Chen H, Deng X, Tu Y, Jackson AO, et al. Perivascular adipose tissue dysfunction aggravates adventitial remodeling in obese mini pigs via NLRP3 inflammasome/IL-1 signaling pathway. Acta Pharmacol Sin. (2019) 40:46-54. doi: 10.1038/s41401-018-0068-9

160. Iacobellis G, Bianco AC. Epicardial adipose tissue: emerging physiological, pathophysiological and clinical features. Trends Endocrinol Metab. (2011) 22:450-7. doi: 10.1016/j.tem.2011.07.003

161. Marchington JM, Mattacks CA, Pond CM. Adipose tissue in the mammalian heart and pericardium: structure, foetal development and biochemical properties. Comp Biochem Physiol B Comp Biochem. (1989) 94:225. doi: 10.1016/0305-0491(89)90337-4

162. Cherian S, Lopaschuk GD, Carvalho E. Cellular cross-talk between epicardial adipose tissue and myocardium in relation to the pathogenesis of cardiovascular disease. Am J Physiol Endocrinol Metab. (2012) 303:E937-49. doi: 10.1152/ajpendo.00061.2012

163. Iacobellis G. Local and systemic effects of the multifaceted epicardial adipose tissue depot. Nat Rev Endocrinol. (2015) 11:363. doi: 10.1038/nrendo.2015.58

164. Bambace C, Sepe A, Zoico E, Telesca M, Olioso D, Venturi S, et al. Inflammatory profile in subcutaneous and epicardial adipose tissue in men with and without diabetes. Heart Vessels. (2014) 29:42-8. doi: $10.1007 / \mathrm{s} 00380-012-0315-9$

165. Aghamohammadzadeh R, Withers S, Lynch F, Greenstein A, Malik R, Heagerty A. Perivascular adipose tissue from human systemic and coronary 
vessels: the emergence of a new pharmacotherapeutic target. Br J Pharmacol. (2012) 165:670-82. doi: 10.1111/j.1476-5381.2011.01479.x

166. Uchida Y, Uchida Y, Shimoyama E, Hiruta N, Kishimoto T, Watanabe S. Human pericoronary adipose tissue as storage and possible supply site for oxidized low-density lipoprotein and high-density lipoprotein in coronary artery. J Cardiol. (2017) 69:236-44. doi: 10.1016/j.jjcc.2016.03.015

167. Vacca M, Di Eusanio M, Cariello M, Graziano G, D’Amore S, Petridis FD, et al. Integrative miRNA and whole-genome analyses of epicardial adipose tissue in patients with coronary atherosclerosis. Cardiovasc Res. (2016) 109:228-39. doi: $10.1093 / \mathrm{cvr} / \mathrm{cvv} 266$

168. Kristensen MM, Davidsen PK, Vigelsø A, Hansen CN, Jensen LJ, Jessen $\mathrm{N}$, et al. miRNAs in human subcutaneous adipose tissue: effects of weight loss induced by hypocaloric diet and exercise. Obesity. (2017) 25:572-80. doi: 10.1002/oby.21765

169. Dai Y, Mehta J. MicroRNA-29, a mysterious regulator in myocardial fibrosis and circulating miR-29a as a biomarker. J Am Coll Cardiol. (2014) 64:2181. doi: 10.1016/j.jacc.2014.03.064

170. Zhao W, Zhao S-P, Zhao Y-H. MicroRNA-143/-145 in cardiovascular diseases. BioMed Res Int. (2015) 2015:531740. doi: 10.1155/2015/531740

171. Fujisaka S, Usui I, Kanatani Y, Ikutani M, Takasaki I, Tsuneyama K, et al. Telmisartan improves insulin resistance and modulates adipose tissue macrophage polarization in high-fat-fed mice. Endocrinology. (2011) 152:1789-99. doi: 10.1210/en.2010-1312

172. Hickson LJ, Prata LGL, Bobart SA, Evans TK, Giorgadze N, Hashmi SK, et al. Senolytics decrease senescent cells in humans: preliminary report from a clinical trial of Dasatinib plus Quercetin in individuals with diabetic kidney disease. EBioMedicine. (2019) 47:446-56. doi: 10.1016/j.ebiom.2019.08.069

173. Conley SM, Hickson LJ, Kellogg TA, McKenzie T, Heimbach JK, Taner T, et al. Human obesity induces dysfunction and early senescence in adipose tissue-derived mesenchymal stromal/stem cells. Front Cell Dev Biol. (2020) 8:197. doi: $10.3389 /$ fcell.2020.00197
174. Palmer AK, Xu M, Zhu Y, Pirtskhalava T, Weivoda MM, Hachfeld CM, et al. Targeting senescent cells alleviates obesity-induced metabolic dysfunction. Aging Cell. (2019) 18:e12950. doi: 10.1111/acel.12950

175. Suetomi T, Willeford A, Brand CS, Cho Y, Ross RS, Miyamoto S, et al. Inflammation and NLRP3 inflammasome activation initiated in response to pressure overload by $\mathrm{Ca}^{2+} /$ calmodulin-dependent protein kinase II $\delta$ signaling in cardiomyocytes are essential for adverse cardiac remodeling. Circulation. (2018) 138:2530-44. doi: 10.1161/CIRCULATIONAHA.118.034621

176. Racioppi L, Noeldner PK, Lin F, Arvai S, Means AR. Calcium/calmodulin-dependent protein kinase kinase 2 regulates macrophage-mediated inflammatory responses. $J$ Biol Chem. (2012) 287:11579-91. doi: 10.1074/jbc.M111.33 6032

177. Jiang H, Xing J, Fang J, Wang L, Wang Y, Zeng L, et al. Tilianin protects against ischemia/reperfusion-induced myocardial injury through the inhibition of the $\mathrm{Ca}^{2+} /$ calmodulin-dependent protein kinase IIdependent apoptotic and inflammatory signaling pathways. BioMed Res Int. (2020) 2020:5939715. doi: $10.1155 / 2020 / 5939715$

Conflict of Interest: The authors declare that the research was conducted in the absence of any commercial or financial relationships that could be construed as a potential conflict of interest.

Copyright (C) 2021 Ruggiero, Key and Kavanagh. This is an open-access article distributed under the terms of the Creative Commons Attribution License (CC BY). The use, distribution or reproduction in other forums is permitted, provided the original author(s) and the copyright owner(s) are credited and that the original publication in this journal is cited, in accordance with accepted academic practice. No use, distribution or reproduction is permitted which does not comply with these terms. 